\title{
Tropical Cyclone Genesis Factors in Simulations of the Last Glacial Maximum
}

\author{
ROBERT L. KORTY \\ Department of Atmospheric Sciences, Texas A\&M University, College Station, Texas \\ SuZANA J. CAMARGO \\ Lamont-Doherty Earth Observatory, Columbia University, Palisades, New York \\ JOSEPH GALEWSKY \\ Department of Earth Sciences, University of New Mexico, Albuquerque, New Mexico
}

(Manuscript received 12 September 2011, in final form 6 December 2011)

\begin{abstract}
Large-scale environmental factors that favor tropical cyclogenesis are calculated and examined in simulations of the Last Glacial Maximum (LGM) from the Paleoclimate Modelling Intercomparison Project Phase 2 (PMIP2). Despite universally colder conditions at the LGM, values of tropical cyclone potential intensity, which both serves as an upper bound on thermodynamically achievable intensity and indicates regions supportive of the deep convection required, are broadly similar in magnitude to those in preindustrial era control simulation. Some regions, including large areas of the central and western North Pacific, feature higher potential intensities at the LGM than they do in the control runs, while other regions including much of the Atlantic and Indian Oceans are lower. Changes in potential intensity are strongly correlated with the degree of surface cooling during the LGM. Additionally, two thermodynamic parameters-one that measures midtropospheric entropy deficits relevant for tropical cyclogenesis and another related to the time required for genesis-are broadly more favorable in the LGM simulation than in the preindustrial era control. A genesis potential index yields higher values for the LGM in much of the western Pacific, a feature common to nearly all of the individual models examined.
\end{abstract}

\section{Introduction}

Observations around the world show that tropical cyclones (TCs) form in places that offer common environmental conditions advantageous for genesis (e.g., see Gray 1968; Camargo et al. 2007). These factors include a surface thermodynamic disequilibrium upon which ocean to atmosphere heat fluxes are predicated, vertical soundings conducive for deep convection, sufficient humidity in the middle troposphere, and low tropospheric wind shear (e.g., Nolan 2011). Each of these factors is influenced by large-scale climate, and they and the climatology of TCs may have differed in other climate states.

Analyses of the portion of the global TC record considered complete, which spans the era of global satellite

Corresponding author address: Robert L. Korty, Department of Atmospheric Sciences, Texas A\&M University, TAMU 3150, College Station, TX 77843-3150.

E-mail: korty@tamu.edu coverage beginning around 1970, showed that both the number of the most intense storms (Webster et al. 2005) and cumulative metrics of cyclone activity (Emanuel 2005) have risen over recent decades. Yet the length of the observational record is short, and Landsea et al. (2006) argued that the underlying completeness and veracity of the estimates contained in these archives limit their utility in climate change analyses (for additional discussion of the underlying nature of the records, see also Landsea 2007; Landsea et al. 2008; Vecchi and Knutson 2008, 2011). Regardless of whether the changes reported in the available data are attributable to any particular climate changes, several modeling studies have predicted that the warmer environment forecast by the end of the current century may support storms whose intensity is higher (Bender et al. 2010; Knutson et al. 2010), while the total number of cyclones in regional (Knutson et al. 2008) and global models (Bengtsson et al. 2007; Emanuel et al. 2008) declines. Tropical cyclone climatology appears to respond to climate in complex ways. 
The burgeoning field of paleotempestology has opened new avenues for studying relationships between TC activity and climate; it employs a variety of geological and geochemical techniques to infer properties of storm activity from periods before modern records existed (Frappier et al. 2007; Nott 2011). One technique for recovering information about past land-falling systems involves studying sedimentary cores taken on the inland side of barrier islands in which sand is deposited only when a storm causes the ocean to wash over the island (e.g., Liu and Fearn 1993, 2000; Donnelly 2005; Donnelly and Woodruff 2007; Marsden et al. 2009). These are limited by the age of the sedimentary record, however, which is generally no longer than the last 3-4 millennia and quite often shorter. More broadly, geologists have seen evidence that TCs affected the geological evolution of islands in the western Pacific (Galewsky et al. 2006; Lin et al. 2008; Hayakawa and Oguchi 2009; Woodruff et al. 2009; Stark et al. 2010), but their interpretations have been hampered by a lack of knowledge of how cyclone tracks and intensity may have changed over the last $\sim 10000$ to $\sim 100000$ years. A few studies have included model simulations of present-day TC tracks to compare with geological evidence (e.g., Cheung et al. 2007; Woodruff et al. 2008), but to date the environmental factors that influence TC genesis have yet to be analyzed in the suite of simulations of recent paleoclimate periods.

A few studies have examined particular TC genesis factors in the model simulations of the warmer late twenty-first century (e.g., Vecchi and Soden 2007a; Emanuel et al. 2008), but the colder climate of the Last Glacial Maximum (LGM) 21000 years ago (21 ka) offers an interesting contrasting case as tropical surface temperatures were much cooler than preindustrial periods (on average $2^{\circ} \mathrm{C}$; e.g., Broccoli 2000). We analyze the coupled ocean-atmosphere model simulations of the LGM produced for the Paleoclimate Modelling Intercomparison Project Phase 2 (PMIP2; Braconnot et al. 2007a) to assess how the environmental factors suitable for tropical cyclogenesis differed in the colder climate. The preindustrial era simulations $(0 \mathrm{ka})$ are taken as the control runs against which these paleoclimate runs are compared. (See section 3 for a discussion of some differences between simulations of the preindustrial era and those of the present day.) The models that we analyze here are coupled ocean-atmosphere simulations, which are crucial when computing thermodynamic variables highly sensitive to surface fluxes; the sea surface temperature (SST) must be free to evolve so as to avoid spurious results in such calculations (Emanuel 2010). While slab ocean runs could also be useful, those with fixed SST would be problematic.

At the LGM, carbon dioxide $\left(\mathrm{CO}_{2}\right)$ was $185 \mathrm{ppm}$, methane was $350 \mathrm{ppm}$, and ice covered a substantial area at high latitudes. Variations in the earth's orbit resulted in a small change in the seasonal distribution of solar radiation, though the difference in orbital parameters between the LGM and today is slight, rendering this change secondary to the major differences in atmospheric composition and surface boundary conditions (Otto-Bliesner et al. 2006). As a result, surface temperatures were substantially colder around the world: about $2^{\circ} \mathrm{C}$ lower in the tropics (Broccoli 2000) and as much as $30^{\circ} \mathrm{C}$ colder over the Laurentide ice sheet (Braconnot et al. 2007a).

In addition to being substantially colder in the tropics, high-latitude ice coverage at the LGM produced sharper temperature gradients in the subtropics. Each LGM simulation exhibited broadly similar patterns of LGM cooling, though the magnitude of the response differs from model to model, primarily over continental locations and in the Southern Hemisphere (Braconnot et al. 2007a). The reduced evaporation and large-scale cooling lead to decreases in tropical precipitation, while the northernmost edge of the intertropical convergence zone (ITCZ) shifts northward by $\sim 2^{\circ}$ latitude in the western Pacific (Braconnot et al. 2007b). Changes in the position of the ITCZ at the LGM in the Atlantic vary from model to model, although there is a southward shift in several.

The purpose of this paper is to investigate how these cold climate changes affect the thermodynamic environment that spawns tropical cyclones. Our specific goals for this analysis are multifold. First, what effects do the large forcing changes at the LGM have on the environment in which TCs form today? Do the forcings result in changes that would permit TC formation in any locations that are presently inhospitable to them or restrict them where today they are common? Are the changes broadly consistent with the analysis of changes reported in warmer climates, such as the late twenty-first century? Finally, what features are common to different models, and which are variable? We hope that the answers to these questions will improve our understanding of the effects of climate on tropical cyclone genesis environments, while also serving broader purposes by providing an avenue for comparing results from geologic research.

We review large-scale environmental factors important to TC genesis and discuss the historical development of genesis indices in section 2. In section 3 we present details about the LGM ensemble and discuss the effects of data processed into long-term climatological means. Section 4 covers the main results of how individual factors change at the LGM, and a summary metric is presented in section 5. Section 6 summarizes our findings. 


\section{Background}

The conditions commonly found at the time of genesis can be partitioned broadly into thermodynamic and kinematic categories, and these environmental factors are principally established by the large-scale climate (e.g., Nolan 2011). Thus, despite the fact that spatial resolutions in global climate models remain too coarse to resolve all of the details necessary for faithful simulations of actual tropical cyclone structure and intensity, they are ideally suited for predicting changes to the macroscopic environment that spawns them. Such analyses have been done for simulations of anthropogenic warming in the present century (e.g., Vecchi and Soden 2007a; Xie et al. 2010), but to date modeling applications for paleoclimates have been more restricted in scope, for example, investigating the possible effect of changes in TC activity on the oceans (Korty et al. 2008; Federov et al. 2010).

The purpose of our paper is to examine how several environmental factors differed in simulations of the LGM. In this section we review the observational and theoretical basis behind particular environmental factors and discuss why some specific formulations are preferable for studies of other climate periods even though alternatives may be equally useful in analyses of the present day. We then discuss how genesis potential indices have been constructed from various combinations of these factors, and briefly review some of the historical progress behind their underlying forms.

\section{a. Genesis factors}

\section{1) THERMODYNAMIC SOUNDINGS}

Early summaries of observations showed that tropical storms rarely form in locations with SST $<26^{\circ} \mathrm{C}$, although even the occasional exception proves that there is no true threshold value. ${ }^{1}$ As theoretical advances over the last quarter century have made clear, however, the fundamental physical requirements for tropical cyclone genesis, intensification, and maintenance include the existence of a thermodynamic disequilibrium at the sea surface to feed the fluxes of enthalpy upon which such storms are predicated (see, e.g., Emanuel 1986). Further, to develop and sustain a tropical cyclone, a boundary layer parcel heated from the fluxes below must then be

\footnotetext{
${ }^{1}$ Indeed some types of polar lows can be regarded, essentially, as hurricanes (e.g., Emanuel and Rotunno 1989). Such systems form during winter months when high-latitude oceans are relatively warm (yet still only slightly above freezing); like their low-latitude counterparts, they feature convectively driven warm cores. However, baroclinic interactions are often also important; see Rasmussen and Turner (2003) for a more thorough overview.
}

able to rise freely through the troposphere by moist convective processes. In the present atmosphere areas where these conditions are commonly met are generally collocated with those whose SST $>26^{\circ} \mathrm{C}$, though, as earlier analyses (e.g., Royer et al. 1998) and our own work (see section 4a) explicitly show, this particular correlation is climate specific.

These coupled processes also establish the upper limit of thermodynamically achievable intensity for the mature phase of a tropical cyclone (e.g., Emanuel 1986; Bister and Emanuel 1998, 2002). This value, called the potential intensity $V_{\mathrm{PI}}$, is set by the thermal structure of the atmosphere; it can be calculated from vertical thermodynamic soundings (see the appendix for further details) and depends on temperatures at the surface (SST) and the convective outflow level $\left(T_{o}\right)$ :

$$
V_{\mathrm{PI}}=\sqrt{\frac{C_{k}}{C_{d}} \frac{\mathrm{SST}-T_{o}}{T_{o}}\left(k_{0}^{*}-k\right) .}
$$

In addition to temperature, the quantity depends on the ratio of the exchange coefficients for enthalpy and drag $\left(C_{k} / C_{d} \approx 1\right)$ and the difference between the saturation specific enthalpy at the sea surface $k_{0}^{*}$ and that of the overlying marine boundary layer $k$. As temperatures in the marine boundary layer are very often near those of the ocean surface, $k_{0}^{*}-k$ is principally determined by the evaporative fluxes that arise because the ocean surface is saturated while the atmosphere above is not.

While $V_{\mathrm{PI}}$ establishes the maximum achievable intensity, it is also useful as a diagnostic for regions supportive of deep tropospheric convection. If a boundary layer parcel were trapped by a low-level inversion, the outflow temperature $T_{o}$ would be substantially warmer than if it could rise unimpeded to the tropopause where $T_{o}$ can fall below $200 \mathrm{~K}$. The need for stability profiles supportive of deep convection noted in early work (Gray 1968) is fundamentally embedded in potential intensity theory, and high and low values of $V_{\text {PI }}$ are bifurcated principally by whether convection is able to reach the upper troposphere (see section 4a for further details and discussion).

\section{2) Midtropospheric Moisture CONTENT}

Incipient tropical cyclones benefit from high relative humidity $(\mathrm{RH})$ in the middle troposphere. Because the large-scale environment at these altitudes is subsaturated, downdrafts can send dry, low entropy air into the boundary layer, which, if strong enough, can overwhelm the inflow of moist, high entropy air fueling convection in the developing system. During the genesis process, persistent convection must saturate the column so that an equilibrium state that sustains moist boundary 
layer inflow and deep vertical convection can be reached (e.g., Nolan 2011).

Although it is natural to consider $\mathrm{RH}$ when evaluating the moisture content of the middle troposphere, axisymmetric hurricane models (e.g., Emanuel 1989, 1995a) have shown that it is the magnitude of the entropy deficit between boundary layer and midtropospheric air compared to the strength of surface fluxes that is the relevant measure during a storm's gestation period. This quantity, defined in those papers as $\chi$, is

$$
\chi=\frac{s_{b}-s_{m}}{s_{0}^{*}-s_{b}},
$$

where $s_{b}, s_{m}$, and $s_{0}^{*}$ are the moist entropies of the boundary layer, middle troposphere (e.g., $600 \mathrm{hPa}$ ), and the saturation entropy at the sea surface, respectively. Lapse rates in the tropics are approximately moist adiabatic as the atmosphere is nearly neutral with respect to moist convection (e.g., Xu and Emanuel 1989; Korty and Schneider 2007), so the boundary layer entropy in these regions is approximately equal to the saturation entropy of the troposphere above it $s_{b} \approx s^{*}$. Thus, the numerator of (2) is approximately equal to the midtropospheric saturation entropy deficit, $s^{*}-s_{m}$. The entropy deficit will change with temperature even if $\mathrm{RH}$ remains constant.

\section{3) WIND SHEAR}

Vertical shear of the horizontal wind (hereafter "shear") is detrimental to genesis and intensification for both dynamic and thermodynamic reasons. It introduces asymmetries in the distribution of convection (Frank and Ritchie 2001) and simultaneously carries with it air from outside the core of the hurricane, which is comparatively dry. Tang and Emanuel (2010) showed that the strength of the ventilation - the product of a midlevel wind anomaly and the entropy difference between the saturated core and environmental air-restricts the potential intensity and ultimately becomes fatal. Moreover, as the ventilation increases, weaker vortices are no longer viable candidates for cyclogenesis (Tang 2010; Tang and Emanuel 2010).

Absent any shear, radiative convective equilibrium (RCE) models show that surface fluxes increase with temperature and can increasingly quickly saturate the midtroposphere (Nolan et al. 2007). But once shear is present-no matter how small-the situation degrades with warming climate: Nolan and Rappin (2008) found that the same models became less favorable for genesis in warming climates in the presence of a constant shear. The reason is thermodynamic: advection of environmental air into the saturated core of a hurricane mixes low entropy air into the system; the absolute saturation deficit grows with the saturation specific humidity if $\mathrm{RH}$ remains nearly constant as SST rises, as was the case in these RCE models. Hence, if the shear is constant, the advection of environmental air becomes increasingly poisonous as the entropy deficit grows with increasing temperature. While stronger surface fluxes could in principle overcome the larger midlevel deficits, in practice they do not grow as rapidly. This renders warmer environments with fixed shear increasingly hostile to development.

\section{4) Absolute vorticity}

It has long been known that tropical cyclones do not arise spontaneously from random convection, but require a "seed" around which to organize (Nolan et al. 2007). This particular requirement, however, is specifically important on smaller spatial and temporal scales relevant to assessing the viability of individual events. In a macroscopic sense, large-scale regions of elevated cyclonic vorticity may yield large numbers of cyclones, but it is less clear whether the vorticity level itself is a rate-limiting factor for genesis. Tippett et al. (2011) showed that cyclonic vorticity appears to be especially important for genesis at very low latitudes where the Coriolis parameter is weak, but that thermodynamic factors appear controlling at higher tropical latitudes. Menkes et al. (2012) confirmed this finding when comparing various genesis indices in the present climate.

\section{b. Genesis potential indices}

In a pioneering effort, Gray (1968) culled and reviewed tropical cyclone observations from discrete locations around the globe and identified environmental conditions that were ubiquitous at the time of their formation. Building on these findings, he introduced an index (Gray 1975, 1979) that empirically fit factors believed to be important for genesis to the available data. These included a SST threshold, thermal soundings, RH, shear, absolute vorticity, and a measure of what would later become known as ocean heat content. Gray's index was generally able to reproduce the regions and timing of TC cyclogenesis (e.g., Watterson et al. 1995), but it was predicated on a specific SST threshold, which is not invariant with climate (e.g., Royer et al. 1998).

Emanuel and Nolan (2004) revisited the approach using an updated, limited number of environmental variables that are expected to remain relevant across different climate states. They included absolute vorticity $\eta$, the magnitude of the 200-850-hPa wind shear vector $V_{\text {sh }}, 600-\mathrm{hPa} \mathrm{RH}$, and the potential intensity of tropical cyclones $V_{\mathrm{PI}}$. By using $V_{\mathrm{PI}}$, the stability requirements noted by Gray (1968) are retained while the climate 
specific correlation between SST and genesis is removed. Emanuel and Nolan (2004) fit these four parameters to observed genesis locations and defined a genesis potential index with the form:

$$
\mathrm{GP}=\frac{a|\eta|^{3 / 2} \mathrm{RH}^{3} V_{\mathrm{PI}}^{3}}{\left(1+0.1 V_{\mathrm{sh}}\right)^{2}}
$$

where both exponents and the normalizing coefficient $a$ were empirically selected for the most advantageous match to observations. Later theoretical and modeling considerations suggested that, for studies of other climate states, the relevant moisture variable is saturation deficits, which change with climate even when RH does not (Emanuel et al. 2008). This led Emanuel (2010) to refine the index:

$$
\mathrm{GP}=\frac{b|\eta|^{3}\left[\max \left(V_{\mathrm{PI}}-35,0\right)\right]^{2}}{\chi^{4 / 3}\left(25+V_{\mathrm{sh}}\right)^{4}},
$$

where wind speeds $\left(V_{\mathrm{PI}}, V_{\mathrm{sh}}\right)$ are entered in $\mathrm{m} \mathrm{s}^{-1}, \eta$ has units of $\mathrm{s}^{-1}$, and $\chi$ is defined by (2). Note that (4) is, by design, dimensionally correct, although the final index values must be scaled by an empirically chosen constant $b$ to conform to a particular dataset.

Recently, Tippett et al. (2011) provided a more rigorous statistical development of the genesis potential and found that the biggest improvements resulted from using a "clipped" vorticity dependence, as the supply of vorticity does not appear to be a rate-limiting factor outside of very low latitudes. An index that depends without restriction on the magnitude of absolute vorticity may overestimate the favorability of subtropical locations where planetary vorticity is high, but thermodynamic factors are marginal today. Based on the findings of Tippett et al. (2011), we modify (4), a form that has been previously applied to different climate states, by clipping the vorticity dependence yielding

$$
\mathrm{GP}=\frac{b\left[\min \left(|\eta|, 4 \times 10^{-5}\right)\right]^{3}\left[\max \left(V_{\mathrm{PI}}-35,0\right)\right]^{2}}{\chi^{4 / 3}\left[25+V_{\text {shear }}\right]^{4}} .
$$

McGauley and Nolan (2011) recently proposed an alternate approach in which they assessed individual genesis factors by the frequency with which each exceeds a threshold value. Genesis potential is maximized when all factors are ubiquitously favorable. We do not yet know if any particular form of these indices would be better suited for a cold climate and defer a more thorough examination of this aspect for future work comparing model-generated vortices with the changes in the thermodynamic environment reported here. In this paper we use (5) as a way to summarize the combined effects of the individual factors, which is the focus of the present work. Additionally, as we discuss further in section 5, there is some recent modeling and theoretical support for a genesis index with a form similar to (5).

\section{Data and temporal averaging}

The data that we analyze were generated for PMIP2, and can be downloaded from an archived database (http://pmip2.lsce.ipsl.fr; see also Braconnot et al. 2007a). For our analysis, we are interested in comparing how each model handles the evolution of large-scale factors in two very different climate periods. The calculation of $V_{\mathrm{PI}}$ requires a vertical sounding with temperature and humidity data at least as frequent as mandatory pressure levels all the way to the lower stratosphere $(\sim 70 \mathrm{hPa}$ in the present climate), which restricts our analysis to the portion of the PMIP2 archive containing data at this resolution. The archive contains some output at monthly and even daily intervals, but many of the individual models offer only a small selection of two-dimensional fields at such frequencies.

The portion of the archive of paleoclimate simulations with suitable vertical resolution is more heavily averaged in time than was used in previous studies, so we have investigated what effects this averaging has on the genesis parameters by revisiting some of the analyses performed on reanalysis data in Camargo et al. (2007). The archive includes data with high vertical resolution for most models in what is termed the "seasonal cycle," in which data were averaged into long-term climatological means for each month of the year (in most cases these were formed from 100-300 years of equilibrium output). Though daily and interannual variability is lost in this averaging, absent a suitable observational record from past millennia against which one could compare such model-generated variability, we do not view this loss as a limitation.

Given that genesis indices are nonlinear, we compared how the results might differ if the order of averaging was reversed. Following Camargo et al. (2007), we used the National Centers for Environmental PredictionNational Center for Atmospheric Research (NCEPNCAR) reanalysis data (Kalnay et al. 1996) to calculate various terms in the Emanuel and Nolan (2004) index (3). We first calculated (3) from monthly data as was done by Camargo et al. for the period 1961-2000 and then computed a climatological average for the genesis index. Second, we calculated monthly climatological means of the four input variables in (3) over the same 40 -yr period and then used these long-term averages to calculate (3). The differences were very small, as were 
TABLE 1. Coupled ocean-atmosphere model members of the PMIP2 archive included in our analysis. The atmospheric data resolution included in the archive are shown, but all data were interpolated onto a common $128 \times 64$ longitude-latitude grid for comparison and ensemble-mean calculations. Only models without flux adjustments and with standard tropospheric vertical resolution were included. [Further details are available in Braconnot et al (2007a,b) and in the database archive at http://pmip2.lsce.ipsl.fr.]

\begin{tabular}{lc}
\hline \multicolumn{1}{c}{ Model } & $\begin{array}{c}\text { Atmospheric resolution } \\
(\text { lon } \times \text { lat } \times \text { level })\end{array}$ \\
\hline CCSM3 & $128 \times 64 \times 17$ \\
CNRM-CM33 & $128 \times 64 \times 16$ \\
ECHAM5-MPIOM1 & $96 \times 48 \times 16$ \\
FGOALS-g1.0 & $128 \times 60 \times 17$ \\
HadCM3M2 & $96 \times 73 \times 15$ \\
IPSL-CM4-V1-MR & $96 \times 72 \times 17$ \\
MIROC3.2 & $128 \times 64 \times 17$ \\
\hline
\end{tabular}

those for individual variables $\left(V_{\mathrm{PI}}\right.$ and $\left.V_{\mathrm{sh}}\right) .^{2}$ Therefore, we believe it is reasonable to use the climatological values stored in the model archive in our analysis, even though interannual differences are lost in the averaging.

The individual genesis factors were computed using each model's wind, temperature, and humidity data on their native grid; the factors were then linearly interpolated onto a common 128 by 64 longitude-latitude grid to compute ensemble means. See Table 1 for ensemble membership and additional detail about the individual models. The LGM ensemble contains seven member simulations and its average is compared to an ensemble average formed from the same seven model's preindustrial simulations.

The control simulation (0 ka) uses trace gas concentrations from circa 1750, which are lower than the twentieth-century climate (preindustrial era values were $280 \mathrm{ppm}$ carbon dioxide, $760 \mathrm{ppb}$ methane, and $270 \mathrm{ppb}$ nitrous oxide), along with a slightly lower value for the 1750 solar constant. These changes make the 0-ka climate slightly cooler than that of the present day, but the differences are small compared to the far larger changes at the LGM. The preindustrial era is taken as a reference climate for comparison in many paleoclimate studies, and it offers the advantage of an equilibrium simulation

\footnotetext{
${ }^{2}$ Ideally one would prefer daily wind data to compute shear, but output at this frequency is not routinely saved for many paleoclimate simulations. The differences between monthly averages of daily shear and shear computed from monthly averaged winds are generally small also, though there are isolated times and locations where the quantities differ by nontrivial amounts. Vecchi and Soden (2007b) also compared averages of the daily shear with the shear of the monthly mean wind in the twenty-first century climate model output and found little difference between the two versions.
}

unencumbered with the additional complications of transient changes in forcings. See Braconnot et al. (2007a) for additional details.

\section{Genesis factors}

In this section we present analysis of the large-scale conditions conducive for tropical cyclone development for both preindustrial era (control: $0 \mathrm{ka}$ ) and LGM (21 ka) simulations of PMIP2. We consider output from seven coupled atmosphere-ocean models for which $21 \mathrm{ka}$ simulations with standard tropospheric vertical resolution are available; see in Table 1 for membership details.

\section{a. Tropical cyclone potential instensity}

The seven-member ensemble mean of tropical cyclone potential intensity $V_{\mathrm{PI}}$ is shown in Fig. 1. Data were computed using the model vertical soundings and SST (see the appendix for further details) for each member's preindustrial control and LGM simulations and then averaged both over peak months in each hemispheric respective storm season and over the seven ensemble members. For the Northern Hemisphere, the season is taken to be July-October (JASO), while in the Southern Hemisphere the season is defined to be JanuaryApril (JFMA); these span the most active months in the observational record and, as will be shown below, correspond to the months of peak genesis potential in simulations of both the preindustrial and LGM climate (see section 5). ${ }^{3}$ Ensemble and storm season mean SSTs are overlaid (black) on contours of the mean $V_{\mathrm{PI}}$ (color). Several features are noteworthy. In the ensemble mean of the control simulations (Fig. 1a), the storm season mean position of the $26^{\circ} \mathrm{C}$ isotherm is collocated with the boundary of regions with mean $V_{\text {PI }}$ greater than $\sim 55 \mathrm{~m} \mathrm{~s}^{-1}$. To first order, there is little broad change in the general location or magnitude of significant $V_{\mathrm{PI}}$ values in the LGM simulations (Fig. 1b), but the isotherm nearest the position of the $55 \mathrm{~m} \mathrm{~s}^{-1}$ contour is $2^{\circ} \mathrm{C}$ cooler than in the 0 -ka control.

The $\sim 55 \mathrm{~m} \mathrm{~s}^{-1}$ contour of the average potential intensity serves as an important division, as values greater than this are found only where deep tropospheric convection occurs. Figure 2 shows the joint distribution of potential intensity and the level of neutral buoyancy (LNB) for 0 ka and the LGM (Figs. 2a and 2c, respectively)

\footnotetext{
${ }^{3}$ Moreover our results throughout the paper are qualitatively insensitive to alternate definitions of the peak storm season, for example August-October in the Northern Hemisphere or DecemberMarch in the Southern Hemisphere.
} 
(a) Oka

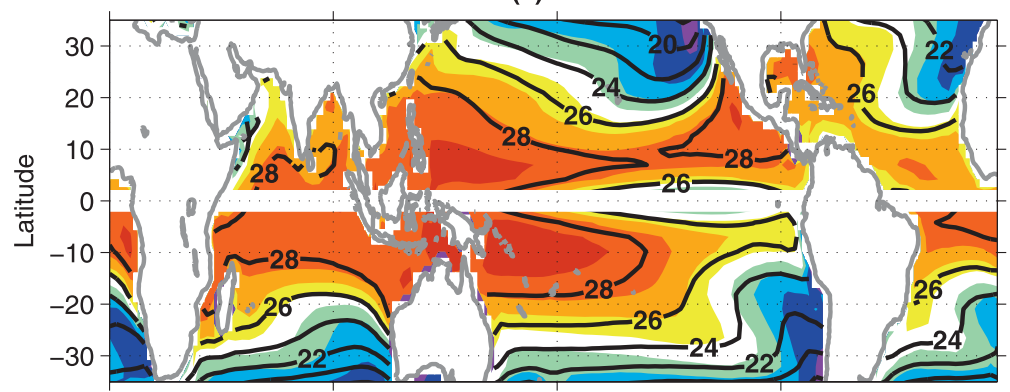

(b) $21 \mathrm{ka}$

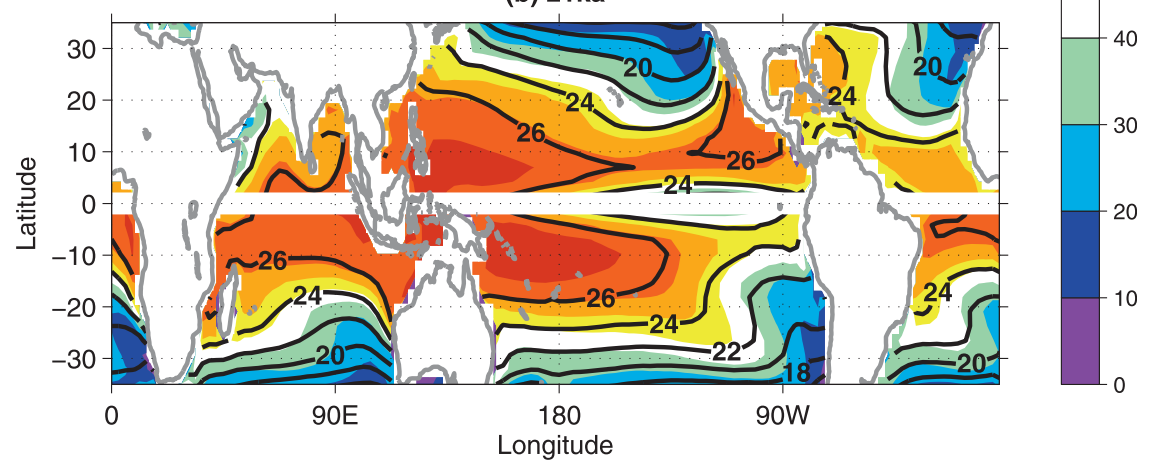

FIG. 1. Ensemble and storm season mean maximum potential intensity ( $\mathrm{m} \mathrm{s}^{-1}$, color) and SST $\left({ }^{\circ} \mathrm{C}\right.$, black) for (a) preindustrial control and (b) the LGM. Storm season is defined as JASO (JFMA) north (south) of the equator. SST contour interval is $2^{\circ} \mathrm{C}$. and the joint distribution of LNB and SST for the two climates (Figs. 2b,d). In Figs. 2a,c there is a clear bifurcation that occurs in both sets of simulations: high values of $V_{\mathrm{PI}}\left(>\sim 55 \mathrm{~m} \mathrm{~s}^{-1}\right)$ occur only when the soundings permit deep tropospheric convection. When soundings limit the LNB to the top of the boundary layer or lower troposphere, the warmer convective outflow temperatures at these altitudes severely restrict the value of $V_{\mathrm{PI}}$, and they are distributed across a range of smaller values most often below $40 \mathrm{~m} \mathrm{~s}^{-1}$. Values of $V_{\text {PI }}$ between 40 and $60 \mathrm{~m} \mathrm{~s}^{-1}$ are uncommon, as the transition from high to low values at any given time in any given model is sharp; because the position of this boundary moves over time, the edge is diffused in the means shown in Fig. 1.

While there is a correlation between the SST and $V_{\mathrm{PI}}$, the relationship is not causal: the clear bifurcation shown in the distributions of $V_{\mathrm{PI}}$ and LNB does not exist in joint distributions of either SST and LNB (Figs. 2b,d) or SST and $V_{\mathrm{PI}}$ (not shown). Both highest $\mathrm{LNB}$ and highest $V_{\mathrm{PI}}$ are found in tropical latitudes where water is warmest, but it is the depth of the convection and the associated cold outflow temperatures that are principally responsible for the high values of $V_{\mathrm{PI}}$ found here. In fact, as is clear in the distributions shown in Figs. $2 d$ and $1 b$, any specific SST that correlates with the highest $V_{\mathrm{PI}}$ values is climate specific: tropical SSTs were approximately $2^{\circ} \mathrm{C}$ lower in the LGM, and the mean position of the $24^{\circ} \mathrm{C}$ isotherm is collocated with the bifurcation of high and low $V_{\mathrm{PI}}$ values in that climate.

Despite universally colder temperatures in LGM simulations, $V_{\mathrm{PI}}$ increases from its $0 \mathrm{ka}$ value in several locations. Figure 3 a shows the difference between the two ensemble-means shown in Fig. 1 with the change in SST overlaid in black. Across a large swath of the central and western North Pacific and in much of the South Pacific, SSTs were less than $2^{\circ} \mathrm{C}$ cooler in the LGM. Here $V_{\mathrm{PI}}$ either changed little or increased from its 0 ka values. In the eastern North Pacific and throughout much of the Atlantic and Indian Oceans, SSTs were $2^{\circ}-3^{\circ} \mathrm{C}$ cooler at the LGM, and potential intensity is generally lower. Figure $3 \mathrm{~b}$ shows that most individual models concur with the sign of the change in $V_{\mathrm{PI}}$ in the ensemble means, indicating that these patterns are robust features found in several different models. Notable exceptions to the ensemble pattern include the North Atlantic in CCSM3, which features higher $V_{\mathrm{PI}}$ there at the LGM than in its 0-ka simulation, and the Flexible Global OceanAtmosphere-Land System Model gridpoint version 1.0 (FGOALS-g1.0), whose $V_{\mathrm{PI}}$ was universally lower at the LGM than its 0-ka simulation.

The correspondence between the degree of SST cooling at the LGM and changes in $V_{\mathrm{PI}}$ is quite strong, as the distribution in Fig. 4a shows. Locations with SSTs that cooled more than $2^{\circ} \mathrm{C}$ are most likely to have lower $V_{\mathrm{PI}}$ 
(a) $0 \mathrm{ka}$

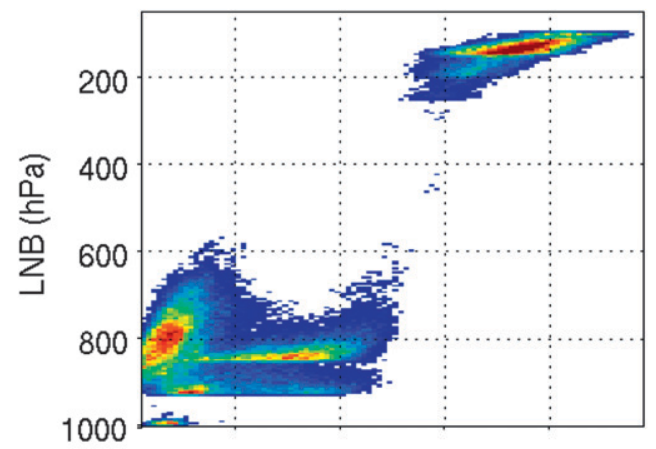

(c) $21 \mathrm{ka}$

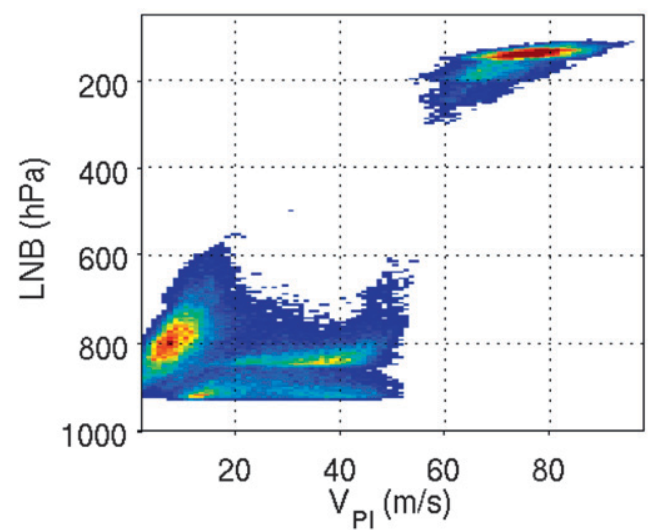

(b) $0 \mathrm{ka}$

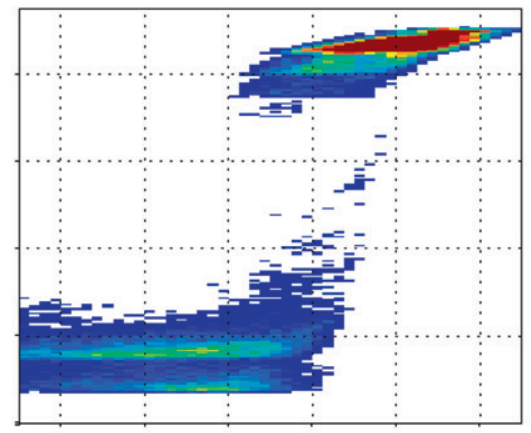

(d) $21 \mathrm{ka}$

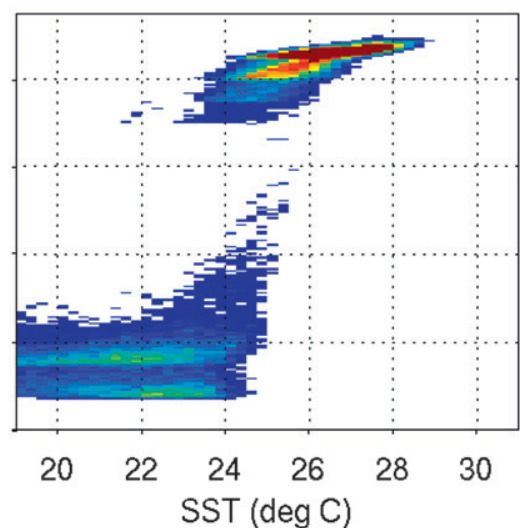

FIG. 2. Histograms of (a) potential intensity $\left(V_{\mathrm{PI}}, \mathrm{m} \mathrm{s}^{-1}\right)$ and level of neutral buoyancy (LNB, hPa) for $0 \mathrm{ka}$ and (b) $\operatorname{SST}\left({ }^{\circ} \mathrm{C}\right)$ and $V_{\mathrm{PI}}\left(\mathrm{m} \mathrm{s}^{-1}\right)$ for $0 \mathrm{ka}$. (c),(d) As in (a),(b) but for the LGM. Data were binned by intervals $1 \mathrm{~m} \mathrm{~s}^{-1}\left(V_{\mathrm{PI}}\right)$, $5 \mathrm{hPa}(\mathrm{LNB})$, and $0.25^{\circ} \mathrm{C}$ (SST) wide. The total number of grid cells from all seven models for all 12 months are counted and plotted; some bins exceeded 300 grid cells, but the color scale is clipped there to retain resolution for lower counts; areas in white have fewer than 20 total grid cells in that bin.

in the LGM than in $0 \mathrm{ka}$; locations with SSTs that cooled by less are likely to have an increase in $V_{\mathrm{PI}}$, even though surface temperatures fell. There is a nearly linear relationship between the degree of SST cooling and change in $V_{\mathrm{PI}}$; a best-fit line has a correlation coefficient of $R=0.81$. Vecchi and Soden (2007a) found that the deviation of the local SST from a larger-scale average was highly correlated with the local $V_{\text {PI }}$ and predicted that a result like that seen in Fig. 4a might arise in simulations of the LGM. Because temperatures in the free troposphere vary little on short time scales and are fairly homogeneous spatially, the larger differences in the marine boundary layer can dominate spatial variability in $V_{\mathrm{PI}}$. Indeed in both simulations of $0 \mathrm{ka}$ (Fig. $4 \mathrm{~b}$ ) and LGM (Fig. 4c), there is a strong linear relationship between the relative SST (defined here as the deviation from the specific model's mean tropical SST for that month) and $V_{\mathrm{PI}}$, with each set having a correlation coefficient $R=$ 0.95 . Although the two quantities are strongly tied to one another, the relative SST does not constrain $V_{\mathrm{PI}}$. For example, locations with SST equal to the tropical mean $\left(\mathrm{SST}^{\prime}=0\right)$ have values of $V_{\mathrm{PI}}$ that spread from $\sim 40$ to $\sim 75 \mathrm{~m} \mathrm{~s}^{-1}$ in both $0 \mathrm{ka}$ and LGM. If temperatures near the tropopause were to change for reasons independent from action at the surface (e.g., a change in lowerstratospheric ozone concentrations), the relationship between relative SST and $V_{\text {PI }}$ would not be as strong. These constraints notwithstanding, it appears that relative SST can be viewed as a zeroth-order approximation for the actual potential intensity, as variations across the boundary layer are generally much more substantial than those of the free troposphere in the tropics.

\section{b. Midtropospheric moisture content}

As noted by Braconnot et al. (2007a), the tropical atmosphere in LGM simulations is drier given the broad cooling and reduced evaporation. But as reviewed in section 2, a relevant moisture parameter for tropical cyclones genesis depends on saturation deficits, which will generally be smaller in cold climates; thus, somewhat 
(a) $\Delta \mathbf{V}_{\mathrm{PI}}$ and $\Delta \mathrm{SST}$

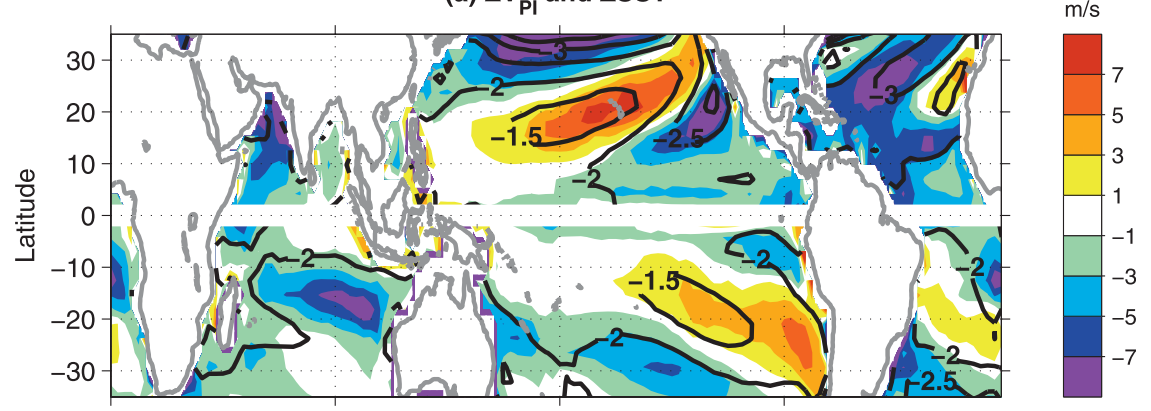

(b) No. models

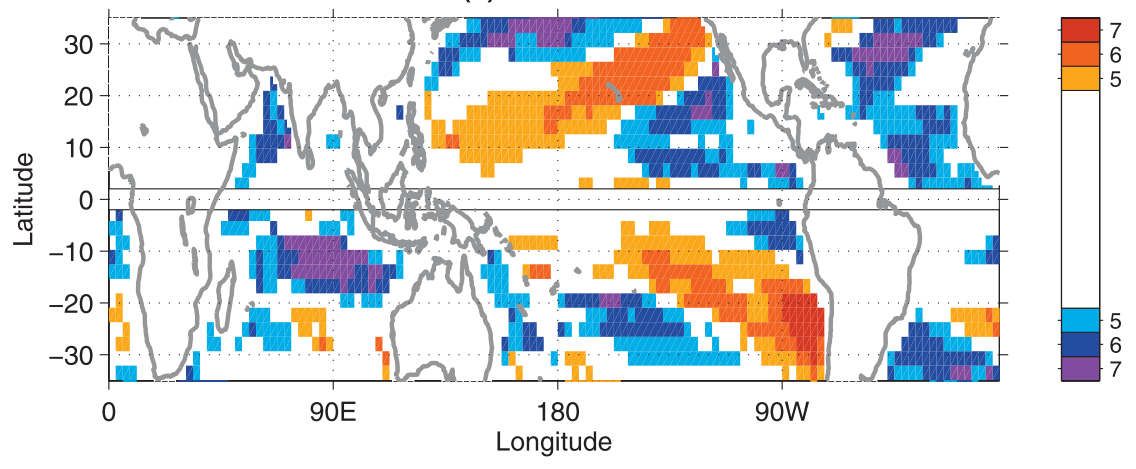

FIG. 3. (a) LGM - 0 ka ensemble mean difference in $V_{\mathrm{PI}}$ (color' $\mathrm{m} \mathrm{s}^{-1}$ ) and SST (black' ${ }^{\circ} \mathrm{C}$; contour interval $0.5^{\circ} \mathrm{C}$ ) during the storm season [JASO (JFMA) north (south) of the equator]. (b) Number of models that agree with the sign of the ensemble average shown in (a); oranges and red correspond to agreement with positive sign change and blues and purples with negative. Areas in white had four or fewer members concur with the sign of the change.

counterintuitively, the low temperatures of the LGM augment the favorability of this facet of the large-scale environment.

The saturation entropy deficit is a function of $\mathrm{RH}$ and of the saturation specific humidity $q^{*}$, which itself is a function of temperature and pressure. The quantity $q^{*}$ is nearly constant in space and time throughout the tropics; hence, seasonal and spatial variations are dominated by changes in $\mathrm{RH}$. When comparing to other climates, however, differences in temperature dominate. Emanuel et al. (2008) showed that $\chi$ increases with global warming because its numerator scales with $q^{*}$, while its denominator scales with surface evaporation rates that do not change much with time. Hence, $\chi$ is larger in warm climates and, as is discussed in the next section, this may result in longer incubation periods for genesis.

Figure 5 shows the spatial distribution of $\chi$ and $\mathrm{RH}$ at $600 \mathrm{hPa}$ for $0 \mathrm{ka}$, LGM, and the difference between the periods. ${ }^{4}$ The colder temperatures at LGM reduce the entropy deficit everywhere (Fig. 5e), even while much of

\footnotetext{
${ }^{4}$ We evaluate $\chi$ using midlevel entropy from $600 \mathrm{hPa}$ and boundary layer entropy from $925 \mathrm{hPa}$. The surface saturation entropy is calculated from surface temperature and pressure data.
}

the tropics have dried in a relative sense. The declines in RH (Fig. 5f) partially offset the influence of lower temperatures on $\chi$, but the temperature dependence dominates the entropy deficit. Hence, in spite of the lower RH of the middle troposphere, the relevant thermodynamic measure has improved: the thermodynamic disequilibrium that is both the denominator of (2) and fuels the surface fluxes on which tropical cyclones depend remains strong, suggesting the environment would have the capacity to quickly saturate middle levels in a developing system. As we discuss in the next section, the lower saturation humidity levels at LGM could reduce the incubation period for a nascent storm.

\section{c. Wind shear}

Large magnitudes of the 200-850-hPa wind shear vector are detrimental to tropical cyclone genesis and intensification (e.g., Gray 1968; DeMaria 1996; Frank and Ritchie 2001). Figure 6 shows the ensemble and storm season mean shear, defined as the magnitude of the 850-200-hPa shear vector, for 0 ka (Fig. 6a) and its change at LGM (Fig. 6b). Shear is generally low in the deep tropics and higher in the subtropics, although there are significant basin and regional differences. The magnitude of the shear vector generally decreases at LGM in 

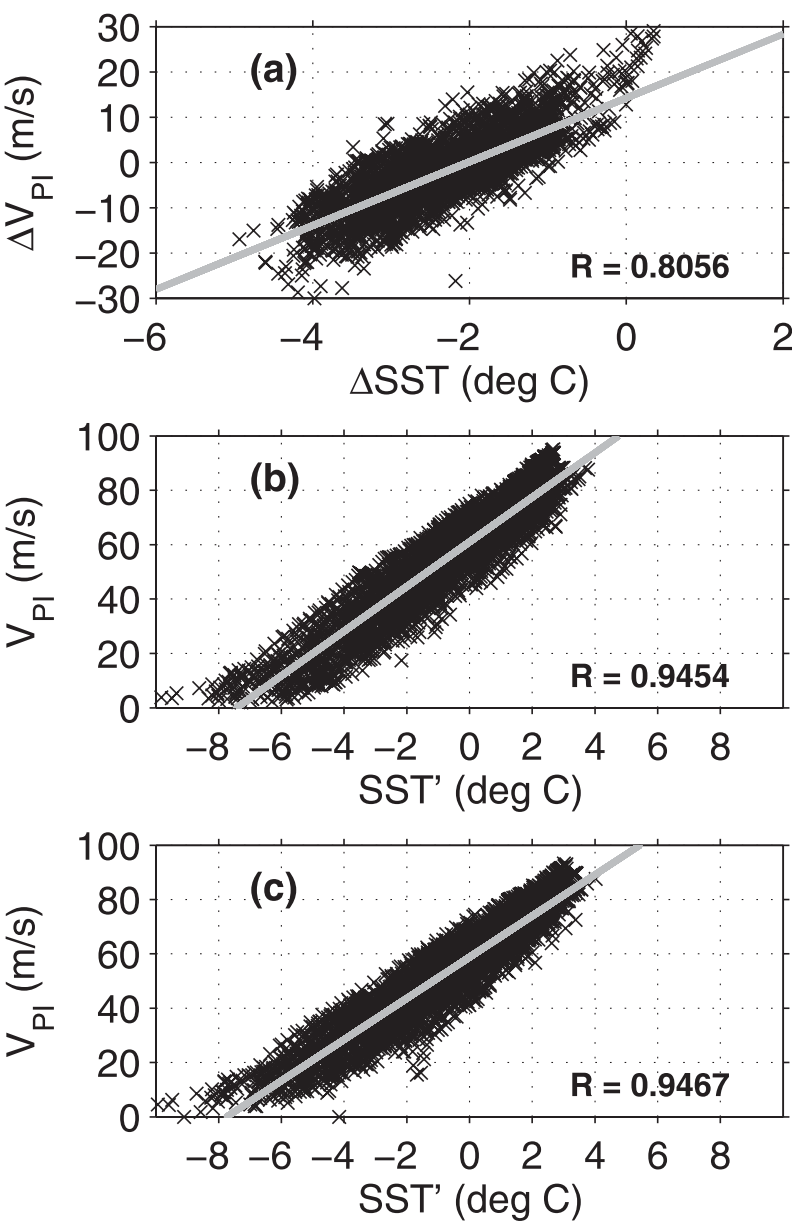

FIG. 4. Scatterplots of (a) the difference in SST and in VPI between the LGM and $0 \mathrm{ka}$ for all Northern Hemisphere grid points between $7^{\circ}$ and $32^{\circ} \mathrm{N}$. The departure of local SST from the tropical mean and VPI (b) in $0 \mathrm{ka}$ and (c) for $21 \mathrm{ka}$. Tropical means are defined here as the average over the $7^{\circ}-32^{\circ} \mathrm{N}$ domain.

the Southern Hemisphere and in the western North Pacific and part of the Atlantic, but it increases elsewhere in the tropical Atlantic and eastern North Pacific.

Beyond any dynamic effects, shear limits tropical cyclone intensity through a thermodynamic effect too (Rappin et al. 2010; Tang and Emanuel 2010). Tang and Emanuel showed that ventilation, which is defined as the product of midlevel wind anomalies and the entropy deficit between the saturated core and environmental air, restricts the intensity a tropical cyclone can achieve. They also showed that there are values of ventilation for which all achievable potential intensities are zero (cf. Fig. 5 of Tang and Emanuel 2010); the point that separates these from nonzero values is related to a nondimensional combination of shear, midlevel entropy deficits, and $V_{\text {PI }}$ (Tang 2010). Interestingly, the same nondimensional parameter appears to be a relevant measure of the time needed for genesis in high-resolution numerical simulations with shear (Rappin et al. 2010):

$$
\gamma=\chi \frac{V_{\mathrm{sh}}}{V_{\mathrm{PI}}} .
$$

This nondimensional parameter $\gamma$-called an "incubation parameter" by Rappin et al. (2010) and a "ventilation index" by Tang (2010) — was an important measure of the viability of nascent systems in the radiative-convective model simulations of genesis done by Rappin et al. Across a range of temperatures, systems failed to develop in simulations when the product of shear and saturation deficits caused $\gamma$ to be large. Viable storms survived in environments with small $\gamma$, with shorter gestation periods for the smallest $\gamma$.

Shear reduces the achievable potential intensity by diluting the thermodynamic efficiency of a tropical cyclone with low entropy environmental air. The degree to which potential intensity is reduced is a function of the product of the shear and saturation deficit (i.e., the numerator of $\gamma$ ), while the denominator normalizes the quantity across different climates (Tang 2010). Thus low shear, low saturation deficits, and high potential intensities both minimize the thermodynamic effects of shear (Tang and Emanuel 2010) and reduce the time required for cyclone genesis and intensification (Rappin et al. 2010). These results enhance the theoretical foundation for their inclusion in the genesis metrics like Eq. (5), which has a form like GP $\sim 1 / \gamma$, although the weightings for particular variables differ (Tang 2010).

Figure 7 shows that the ventilation index and incubation parameter are lowest in the regions that spawn tropical cyclones today (Fig. 7a) and generally decreases in magnitude at the LGM (Fig. 7b), although lower $V_{\mathrm{PI}}$ and higher wind shears lead to similar or elevated values in the eastern North Pacific and parts of the western Atlantic. Elsewhere the departure is generally negative, suggesting that the colder environment at the LGM may be broadly more favorable for tropical cyclone formation in an important sense: if surface fluxes remain robust, the smaller midtropospheric entropy deficits common in colder climates could mitigate the detrimental effects of dry air ventilation manifested by wind shear.

\section{Genesis potential index}

As reviewed in section $2 \mathrm{~b}$, genesis potential indices have proven to be a useful way of summarizing the environmental favorability for tropical cyclone formation. We evaluate the form given by (5) to summarize the collective changes to the environment, but emphasize that any particular formulation could be climate or 
(a) $\chi 0$ ka

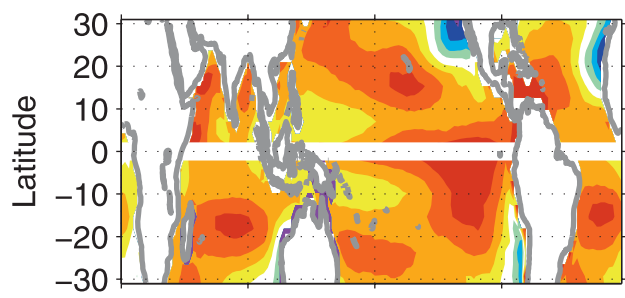

(c) $\chi 21 \mathrm{ka}$

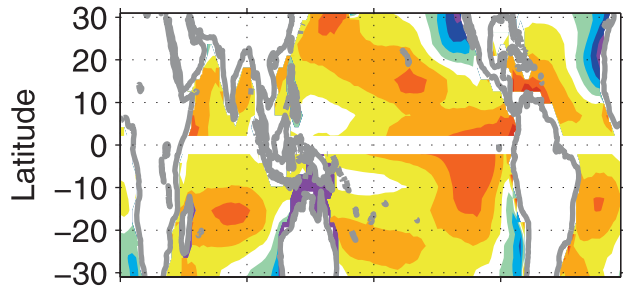

(e) $\Delta \chi 21 \mathrm{ka}-0 \mathrm{ka}$

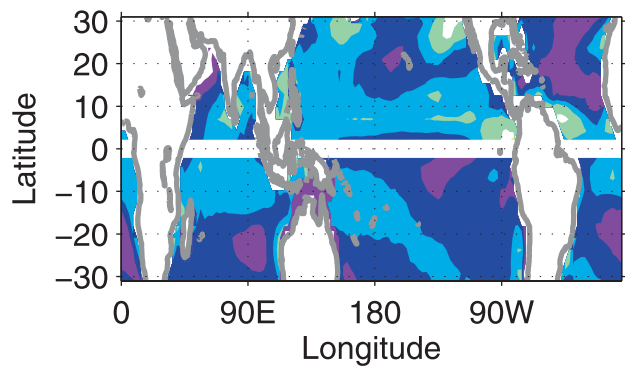

(b) RH Oka

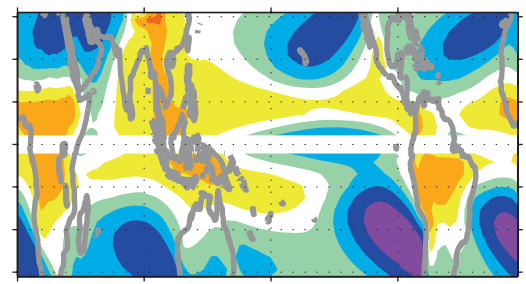

(d) RH $21 \mathrm{ka}$

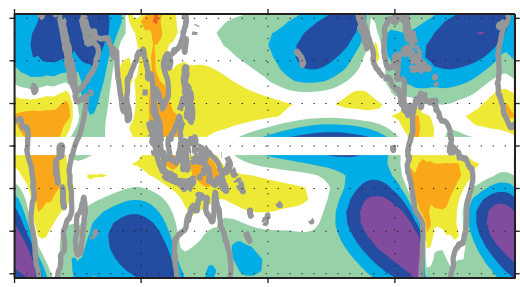

(f) $\triangle$ RH 21ka-0ka

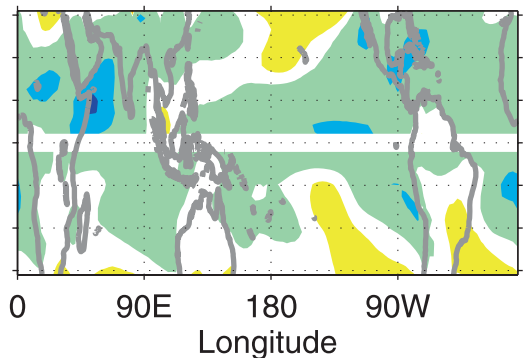

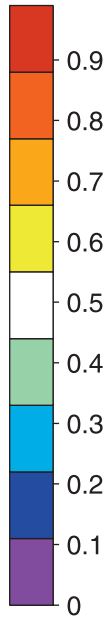

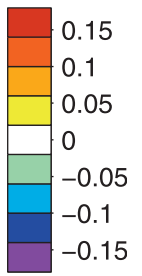

FIG. 5. Ensemble and storm season mean nondimensional entropy deficit parameter $\chi$ for (a) $0 \mathrm{ka}$, (c) $21 \mathrm{ka}$, and (e) difference between $21 \mathrm{ka}$ and $0 \mathrm{ka}$; and ensemble and storm season mean relative humidity (fraction) at $600 \mathrm{hPa}$ for (b) $0 \mathrm{ka}$, (d) $21 \mathrm{ka}$, and (f) difference between $21 \mathrm{ka}$ and $0 \mathrm{ka}$ : storm season defined as in Fig. 3 . model specific. We postpone such questions for later work and present the results of (5) as a way to summarize the key findings.

The multimodel ensemble mean for $0 \mathrm{ka}$ is shown in Fig. 8a, and the difference in the ensemble average at the LGM is shown in Fig. 8b; the number of models concurring with the sign change is shown in Fig. 8c..$^{5}$ Across much of the Pacific, particularly in the western part of the basin, conditions in the LGM favor higher $V_{\mathrm{PI}}$ (Fig. 3a), lower $\chi$ (Fig. 5c), and weaker shear (Fig. 6b). Each of these individually works to reduce the incubation parameter (Fig. 7b) and increase genesis potential (Fig. 8b). Note that all of the individual factors examined point to more

\footnotetext{
${ }^{5}$ Although what matters here is the distribution of GP values and how they differ between $0 \mathrm{ka}$ and the LGM, (5) offers an additional advantage in that its units are number of events per area per time. After multiplying the GP of each grid point by its area and converting units, (5) can be expressed in number of events per month, though the results must still be scaled by the coefficient $b$ to be meaningful. To normalize annual global storm counts in $0 \mathrm{ka}$ to 85 , a number close to the total observed, we set $b=1 / 1500$.
}

favorable conditions in the western Pacific at the LGM. In the Southern Hemisphere Indian Ocean and along the northern edge of high genesis potential in the eastern North Pacific, lower $V_{\text {PI }}$ and higher shears drag genesis potential down despite universal decreases in $\chi$; both of these regions lie above oceans that cooled by a larger than average amount in the tropics. Lower $V_{\mathrm{PI}}$ in the North Atlantic also lead to slightly lower genesis potential in most models, but the changes are small as a decrease in $\chi$ and mixed changes in shear partially compensate.

The majority of the models agree with the general changes in the ensemble mean (Fig. 8c), but there is some variability across the individual simulations, as shown in Fig. 9. FGOALS-g1.0 and L'Institut Pierre-Simon Laplace (IPSL) differ most from the other members across the Pacific; the LGM simulation of FGOALS, which has lower native resolution (see Table 1), features lower $V_{\mathrm{PI}}$ throughout the Pacific, which leads to the broad swath of lower GP values across the basin. There is less agreement on the magnitude or even sign of the changes in the Atlantic. Yet in a broader sense one remarkable feature is noteworthy: despite differences in 
(a) Shear Oka

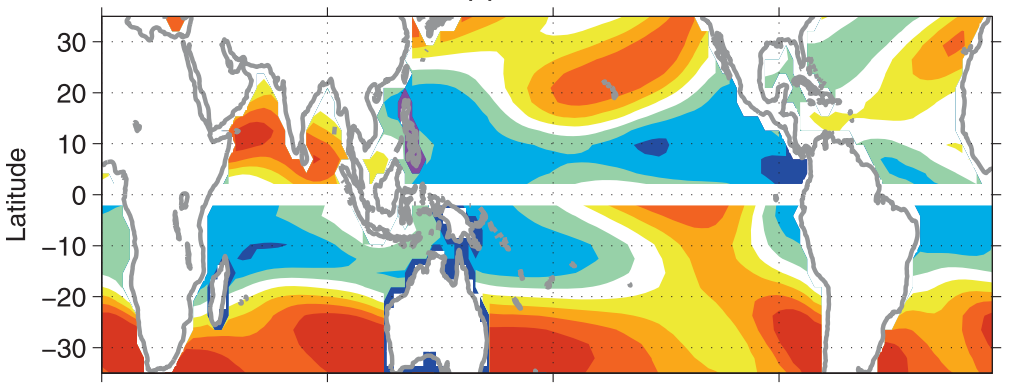

(b) $\Delta$ Shear 21ka-0ka

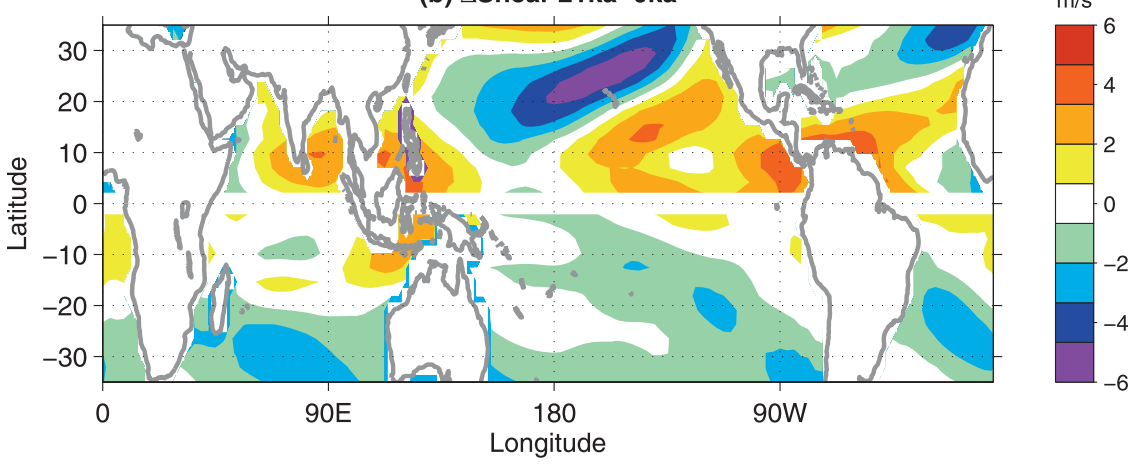

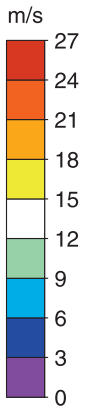

$\mathrm{m} / \mathrm{s}$

FIG. 6. (a) Ensemble and storm season mean of magnitude of 850-200-hPa shear vector in 0 -ka simulations and (b) difference in ensemble and storm season mean of the magnitude of the 850-200-hPa wind shear vector between LGM and 0 ka: Storm season as in Fig. 3.

the magnitude and precise location of particular changes at the LGM, each model shows a mixture of increases and decreases in GP. That is, there is no monotonic shift toward broadly lower GP in any model, despite the substantially colder climate. Integrating the GP for each calendar month over the area of the oceans yields a seasonal cycle, which is shown in Fig. 10. The seasonal cycle of hemispherically integrated genesis potential differs little between the LGM and $0 \mathrm{ka}$ in both hemispheres (a fact that we use to justify defining storm seasons to be the same in both $0 \mathrm{ka}$ and LGM). The global total was normalized to 85 events in 0 ka by setting $b=1 / 1500$ in (5); retaining this value yields an annual total of 91 for the LGM.

In summary, despite the universally colder conditions at the LGM, many tropical cyclone genesis factors become more favorable. Potential intensity rises in many parts of the Pacific where SST cooled by less than the $2^{\circ} \mathrm{C}$ tropical average; this is broadly consistent with the arguments made by Vecchi and Soden (2007a). Emanuel et al. (2008) argued that the decrease in TC counts seen in global model simulations of the warmer late twentyfirst century could be attributed to increasing saturation deficits with rising temperature. A corollary to this argument is that colder climates such as the LGM may be more suitable for genesis as the time needed for nascent convection to saturate the midtroposphere is reduced.

\section{Summary}

We investigated how thermodynamic environmental factors important to tropical cyclone genesis differ in simulations of the LGM from their values in the preindustrial control. Despite the universally colder conditions at the LGM, many TC genesis factors become more favorable. Potential intensity rises in much of the central and western North Pacific during JASO and it is similar to or higher than 0 ka values in most of the South Pacific during JFMA; water temperatures were cooler at LGM by less than the tropical average of $2^{\circ} \mathrm{C}$ in these regions during their respective storm seasons. Where water temperatures cooled more than the average amount (e.g., North Atlantic, eastern North Pacific, and south Indian Oceans), $V_{\mathrm{PI}}$ was lower at the LGM than $0 \mathrm{ka}$. Most individual members agreed with the general patterns observed in the ensemble mean.

Though it may appear surprising that values of $V_{\mathrm{PI}}$ are broadly similar and even locally higher at the LGM compared to $0 \mathrm{ka}$ despite the universally lower temperatures, the results underscore how misleading relationships between SST and tropical cyclones can be. 


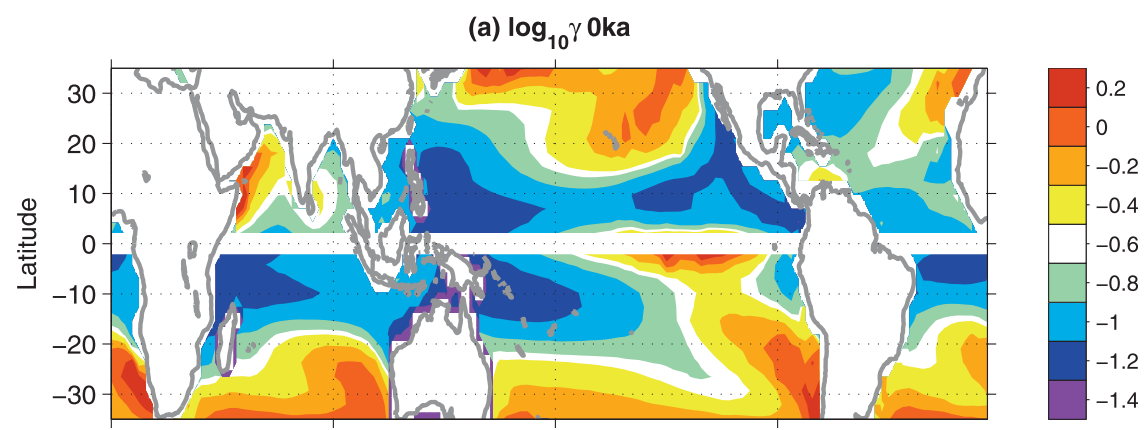

(b) $\Delta\left(\log _{10} \gamma\right) 21 \mathrm{ka}-0 \mathrm{ka}$

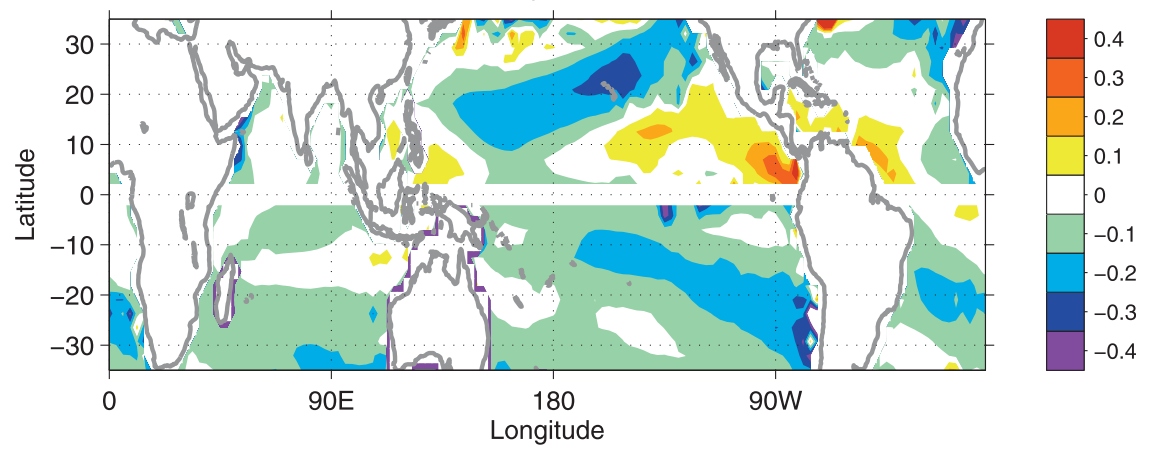

FIG. 7. (a) Base-10 logarithm of ensemble and storm season mean incubation parameter $\gamma$ in $0 \mathrm{ka}$ and (b) change in the base-10 logarithm of the ensemble and storm season mean $\gamma$ between LGM and 0 ka: Storm season as in Fig. 3.

The surface thermodynamic disequilibrium, which affects $V_{\text {PI }}$ via (1), can be related to radiative and heat fluxes by considering the equilibrium energy balance (Emanuel 2010):

$$
k_{0}^{*}-k=\frac{-F_{\mathrm{sfc}}+F_{o c}}{C_{k} \rho\left|\mathbf{V}_{s}\right|}
$$

Here $F_{\text {sfc }}$ is the net upward radiative flux at the sea surface, $F_{o c}$ is the net convergence of heat flux in the ocean, $\rho$ is the density of air at the surface, and $\left|\mathbf{V}_{s}\right|$ is the surface wind speed; all other variables have the same meaning as before. If changes in $\mathrm{CO}_{2}$ were the principal driver behind changes in SST, then both it and the enthalpy difference in (7) would be lower as a result of decreased $F_{\text {sfc }}$ (unless there were compensation in the ocean and/or surface wind speeds). Yet if the atmospheric heat flux increased, as it does during LGM at tropical latitudes during the late summer and early autumn storm seasons in many of the models examined here, tropical SST would decline even while the quantities in (7) were unaffected, resulting in little change to $V_{\mathrm{PI}}$ via (1) (K. Emanuel 2011, personal communication). During other periods in which $F_{\text {sfc }}$ changes (e.g., in response to rising $\mathrm{CO}_{2}$ levels) both SST and $V_{\mathrm{PI}}$ may change in tandem, so the results here might not prove to be a useful analog for climate change in the next century.

Several other of our calculations are broadly consistent with findings reported in earlier work on warmer climates of the late twenty-first century. Emanuel et al. (2008) argued that the decrease in Atlantic TC counts seen in regional model simulations of the warmer late twenty-first century could be attributed to increasing saturation deficits with temperature. A corollary to this argument is that colder climates such as the LGM may be more suitable for genesis as the time needed for nascent convection to saturate the midtroposphere is reduced. Combined with weaker wind shears in the central and western North Pacific and through much of the Southern Hemisphere, the incubation parameter (Rappin et al. 2010) and ventilation index (Tang and Emanuel 2010) decreases at LGM. These factors individually and in combination support higher genesis potential in much of the western and central Pacific, while genesis potential declines in the southern Indian Ocean; changes in the Atlantic are mixed and differ from model to model.

A next step is to examine whether various downscaling techniques and global models' own climatology of TC-like vortices change in ways consistent with the findings reported here. The PMIP2 archive does not 
(a) GP Oka

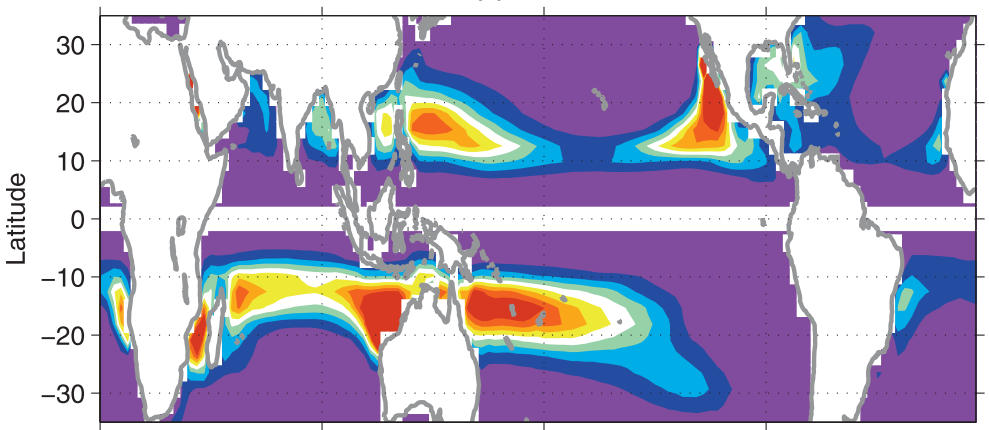

(b) $\triangle$ GP 21ka-0ka

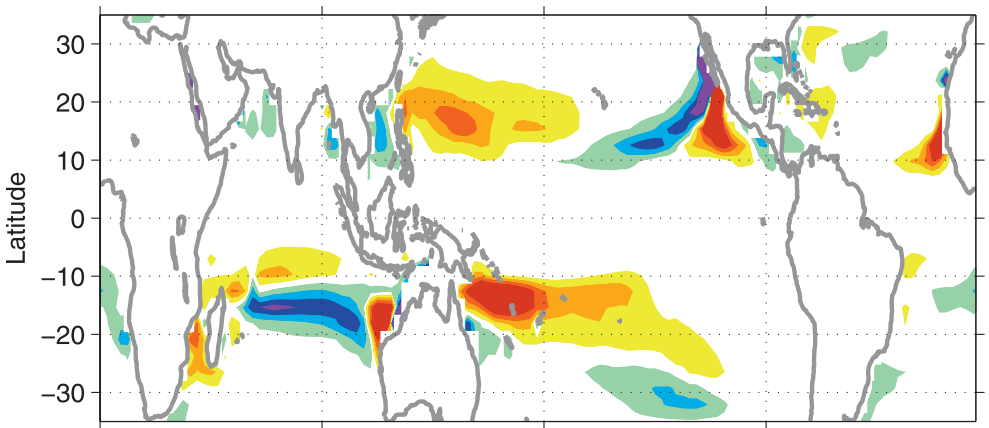

(c) No. models

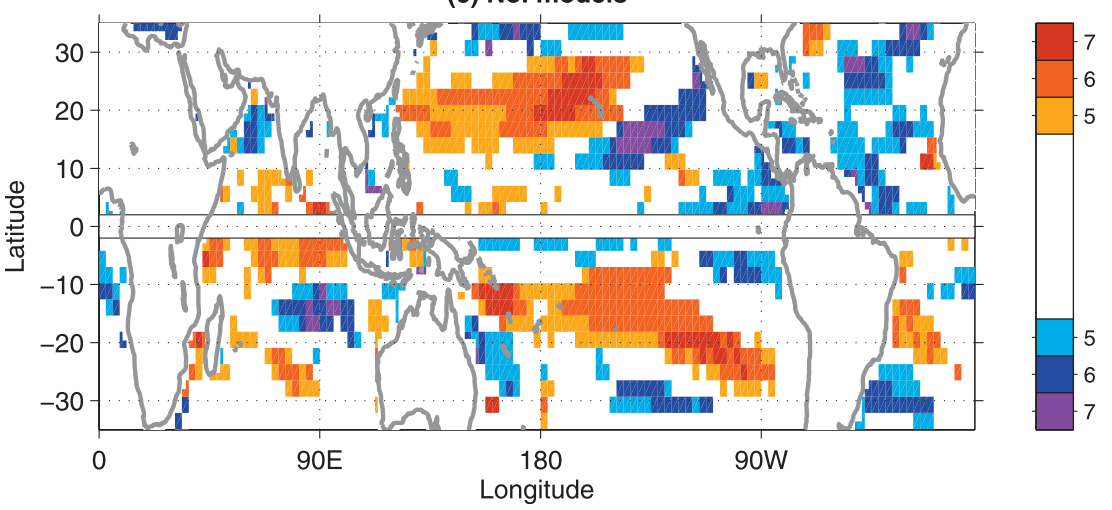

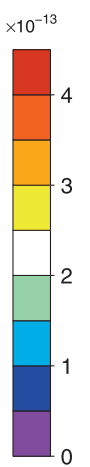

$\times 10^{-13}$

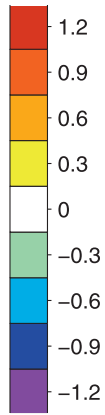

$-1.2$

FIG. 8. (a) Storm season (JASO north of equator and JFMA south of it) and ensemble mean genesis potential for $0 \mathrm{ka}$. (b) Change in storm season ensemble mean genesis potential between LGM and $0 \mathrm{ka}$. (c) Number of individual models concurring with the sign change of the ensemble mean shown in (b). The units of genesis potential are events $\mathrm{m}^{-2}$ month $^{-1}$.

include sufficient temporal resolution to track and analyze model generated vortices in each member model, and some models were run at a resolution too low for tracking algorithms [generally T42 or higher is required, Camargo and Zebiak (2002); Camargo and Sobel (2004)], which necessitates deferring such analyses for new runs with higher resolution. In subsequent work we will explore whether the general changes in tropical cyclone genesis factors reported here are manifested in the tracks and climatology of modelgenerated vortices in addition to simulations of individual storms in high-resolution models designed to simulate them properly.

Acknowledgments. We gratefully acknowledge the many international modeling groups who made their data available for analysis and the Laboratoire des Sciences du Climat et de l'Environement (LSCE) for collecting, archiving, and distributing these simulations. The analyses were performed using the version of the PMIP2 database present on 8 June 2011 (additional information is available online at http://pmip2.lsce.ipsl.fr). 


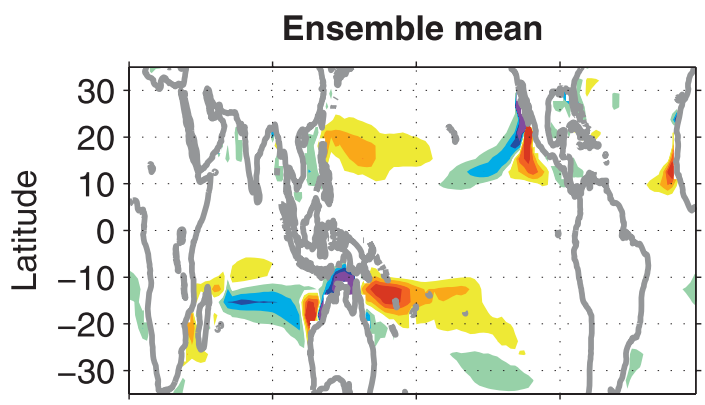

CNRM

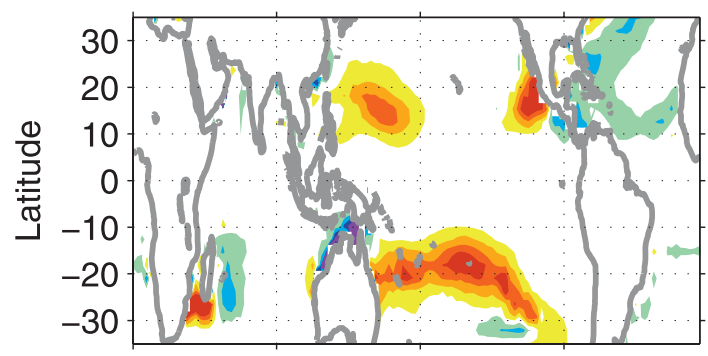

FGOALS

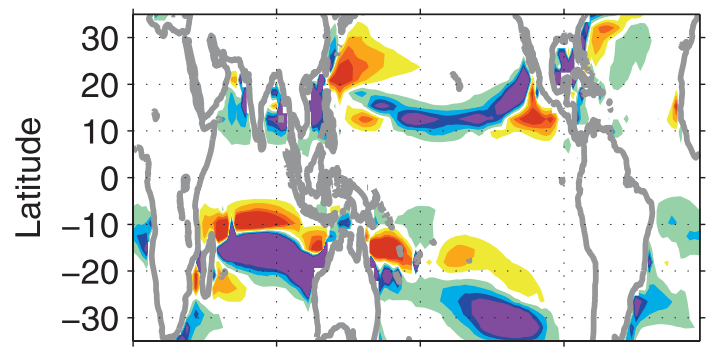

IPSL

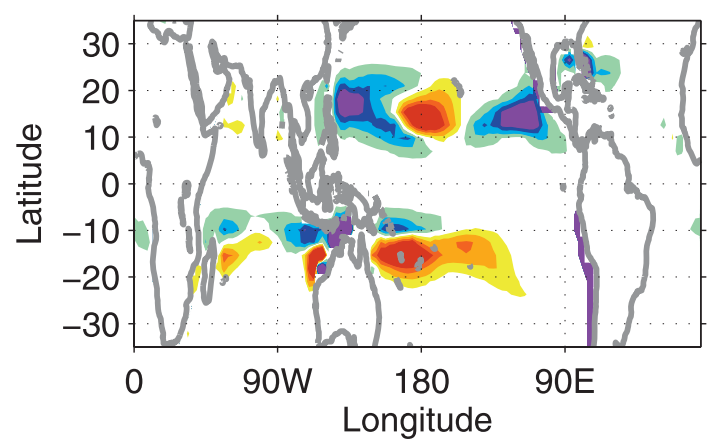

\section{CCSM}

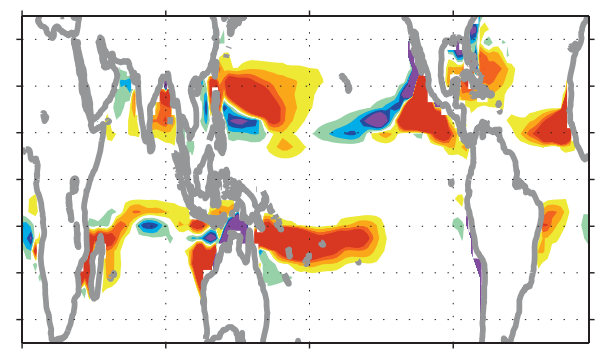

ECHAM5

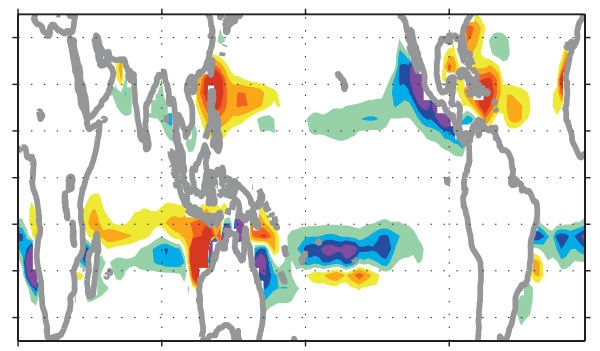

HadCM3

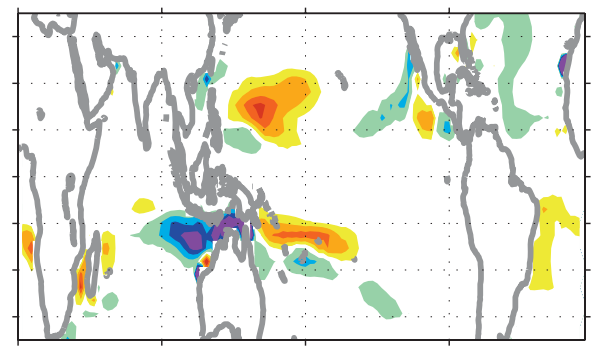

MIROC

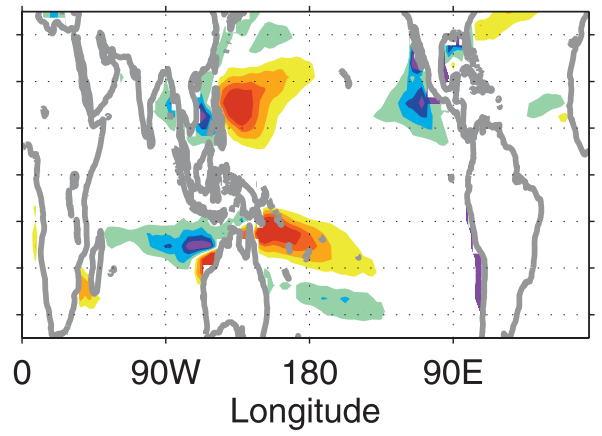

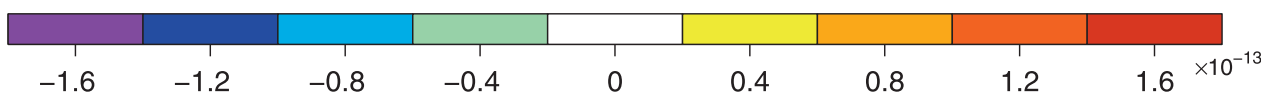

FIG. 9. As in Fig. 8b, but for individual members of the ensemble. Units are events $\mathrm{m}^{-2} \mathrm{month}^{-1}$.

We thank Bette Otto-Bliesner for helpful discussions and her advice and support on the project, and we thank Kerry Emanuel for several useful comments, in particular for pointing out the relationship between the surface energy budget and thermodynamic disequilibrium.
We thank an anonymous reviewer for many helpful comments. Ryan Zamora and Nicholas Adams assisted with data processing. The National Science Foundation supported this study through Grants ATM-1064013, ATM-1064081, and ATM-1063837. 
(a) Northern Hemisphere

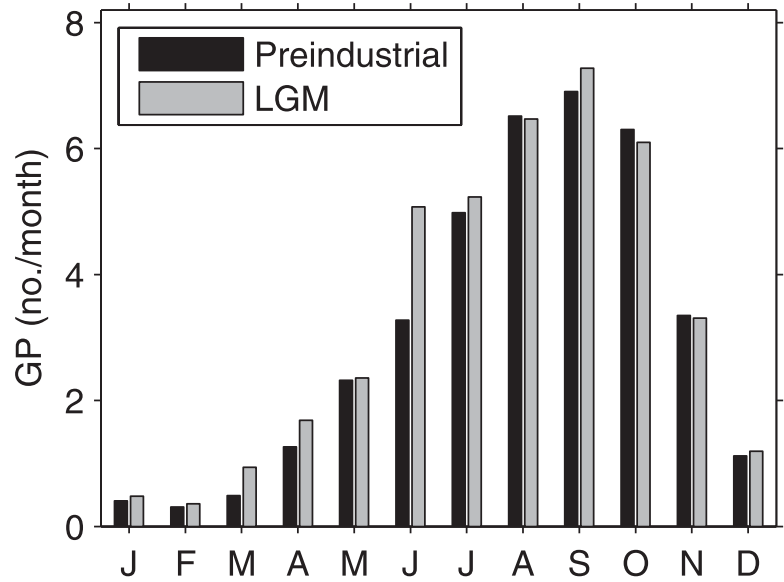

(b) Southern Hemisphere

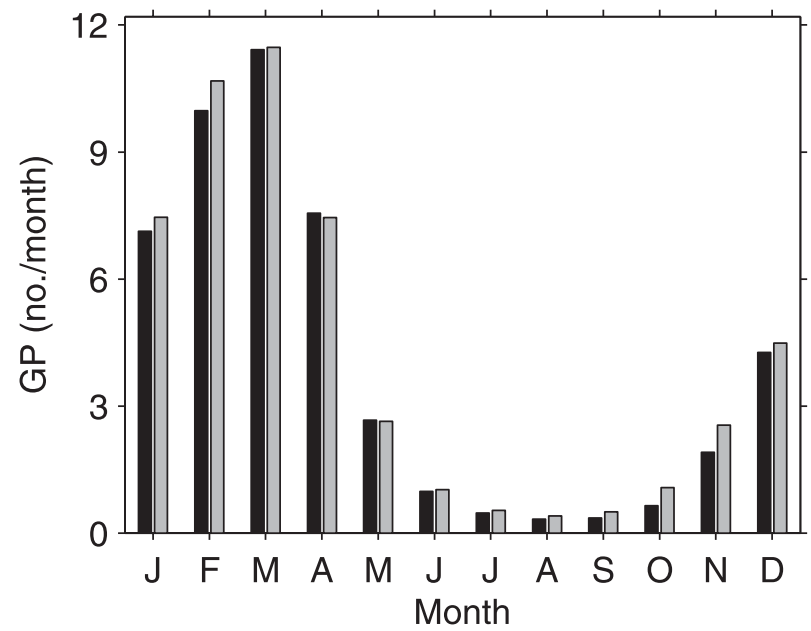

FIG. 10. Seasonal cycle of (a) Northern Hemisphere and (b) Southern Hemisphere genesis potential for preindustrial control (black) and LGM (gray). The coefficient $b$ in (5) was set to $1 / 1500$, and units are number of events per month. This choice of $b$ yields 85 events $\mathrm{yr}^{-1}$ globally in the preindustrial control; the annual global sum is 91 for LGM.

\section{APPENDIX}

\section{Potential Intensity}

The initial derivation of potential intensity was presented in papers by Emanuel $(1986,1995 b)$ and was later modified to account for the effects of dissipative heating (Bister and Emanuel 1998). Bister and Emanuel (2002) present a detailed description of how to calculate the quantity from vertical soundings of temperature and humidity, and they show the formula given by (1) can be expressed alternatively in terms of the convective available potential energy (CAPE) derived from a thermodynamic sounding. Written this way, potential intensity is given by

$$
V_{\mathrm{PI}}=\sqrt{\frac{C_{k}}{C_{d}} \frac{\mathrm{SST}_{0}}{T_{o}}\left(\mathrm{CAPE}^{*}-\mathrm{CAPE}^{b}\right)},
$$

where variables have the same meanings as used throughout the text (for additional detail, see Bister and Emanuel 2002). CAPE is the vertical integral of parcel buoyancy, which depends upon parcel temperature, pressure, and specific humidity. The term CAPE* in (A1) is the value of CAPE for an air parcel at the radius of maximum winds that has first been saturated at the temperature and pressure of the sea surface. $\mathrm{CAPE}^{b}$ is the value of CAPE for an ambient boundary layer parcel of air whose pressure is reduced isothermally to that of the radius of maximum wind. Thus, to calculate potential intensity, one needs the SST, surface pressure, and vertical profiles of temperature and humidity at each grid point. We use the FORTRAN algorithm (made available by $\mathrm{K}$. Emanuel at ftp://texmex.mit.edu/pub/emanuel/ TCMAX). Soundings should have vertical resolution of temperature at least as frequent as mandatory tropospheric pressure levels and extend into the lower stratosphere $(\sim 70 \mathrm{hPa})$; humidity levels from the boundary layer are necessary, but they are unimportant at higher altitudes (K. Emanuel 2011, personal communication).

\section{REFERENCES}

Bender, M. A., T. R. Knutson, R. E. Tuleya, J. J. Sirutis, G. A. Vecchi, S. T. Gardner, and I. M. Held, 2010: Modeled impact of anthropogenic warming on the frequency of intense Atlantic hurricanes. Science, 327, 454-458.

Bengtsson, L., K. I. Hodges, M. Esch, N. Keenlyside, L. Kornblueh, J.-J. Luo, and T. Yamagata, 2007: How may tropical cyclones change in a warmer climate? Tellus, 59A, 539-561.

Bister, M., and K. A. Emanuel, 1998: Dissipative heating and hurricane intensity. Meteor. Atmos. Phys., 52, 233-240.

_, and _ 2002: Low frequency variability of tropical cyclone potential intensity: 1 . Interannual to interdecadal variability. J. Geophys. Res., 107, 4801, doi:10.1029/2001JD000776.

Braconnot, P., and Coauthors, 2007a: Results of PMIP2 coupled simulations of the Mid-Holocene and Last Glacial Maximum. Part 1: Experiments and large-scale features. Climate Past, 3, 261-277.

— and Coauthors, 2007b: Results of PMIP2 coupled simulations of the Mid-Holocene and Last Glacial Maximum. Part 2: Feedbacks with emphasis on the location of the ITCZ and midand high latitudes heat budget. Climate Past, 3, 279-296.

Broccoli, A. J., 2000: Tropical cooling at the Last Glacial Maximum: An atmosphere-mixed layer ocean model simulation. J. Climate, 13, 951-976.

Camargo, S. J., and S. E. Zebiak, 2002: Improving the detection and tracking of tropical cyclones in atmospheric general circulation models. Wea. Forecasting, 17, 1152-1162.

— , and A. H. Sobel, 2004: Formation of tropical storms in an atmospheric general circulation model. Tellus, 56A, 56-67.

- — - A. G. Barnston, and K. A. Emanuel, 2007: Tropical cyclone genesis potential index in climate models. Tellus, 59A, 428-443. 
Cheung, K. F., L. J. Tang, J. P. Donnelly, E. M. Scileppi, K. B. Liu, X. Z. Mao, S. H. Houston, and R. J. Murnane, 2007: Numerical modeling and field evidence of coastal overwash in southern New England from Hurricane Bob and implications for paleotempestology. J. Geophys. Res., 112, F03024, doi:10.1029/ 2006JF000612.

DeMaria, M., 1996: The effect of vertical shear on tropical cyclone intensity change. J. Atmos. Sci., 53, 2076-2087.

Donnelly, J. P., 2005: Evidence of past intense tropical cyclones form backbarrier salt pond sediments: A case study from Isla de Culebrita, Puerto Rico, USA. J. Coast. Res., 42, 201-210.

— , and J. D. Woodruff, 2007: Intense hurricane activity over the past 5000 years controlled by El Niño and the West African monsoon. Nature, 447, 465-468.

Emanuel, K. A., 1986: An air-sea interaction theory for tropical cyclones. Part I: Steady-state maintenance. J. Atmos. Sci., 43, 585-604.

_ 1989: The finite-amplitude nature of tropical cyclogenesis. J. Atmos. Sci., 46, 3431-3456.

_, $1995 \mathrm{a}$ : The behavior of a simple hurricane model using a convective scheme based on subcloud-layer entropy equilibrium. J. Atmos. Sci., 52, 3959-3968.

$\ldots, 1995 \mathrm{~b}$ : Sensitivity of tropical cyclones to surface exchange coefficients and a revised steady-state model incorporating eye dynamics. J. Atmos. Sci., 52, 3969-3976.

- 2005: Increasing destructiveness of tropical cyclones over the past 30 years. Nature, 436, 686-688.

- 2010: Tropical cyclone activity downscaled from NOAACIRES reanalysis, 1908-1958. J. Adv. Model. Earth Syst., 2, 12 pp., doi:10.3894/JAMES.2010.2.1.

_ , and R. Rotunno, 1989: Polar lows as arctic hurricanes. Tellus, 41A, $1-17$.

, and D. S. Nolan, 2004: Tropical cyclone activity and the global climate system. Preprints, 26th Conf. on Hurricanes and Tropical Meteorology, Miami, FL, Amer. Meteor. Soc., 10A.2. [Available online at http://ams.confex.com/ams/26HURR/ techprogram/paper_75463.htm.]

—, R. Sundararajan, and J. Williams, 2008: Hurricanes and global warming: Results from downscaling IPCC AR4 simulations. Bull. Amer. Meteor. Soc., 89, 347-367.

Federov, A. V., C. M. Breierly, and K. Emanuel, 2010: Tropical cyclones and permanent El Niño in the early Pliocene epoch. Nature, 463, 1066-1070.

Frank, W. M., and E. A. Ritchie, 2001: Effects of vertical wind shear on the intensity and structure of numerically simulated hurricanes. Mon. Wea. Rev., 129, 2249-2269.

Frappier, A., T. Knutson, K.-B. Liu, and K. Emanuel, 2007: Perspective: Coordinating paleoclimate research on tropical cyclones with hurricane-climate theory and modeling. Tellus, 59A, 529-537.

Galewsky, J., C. P. Stark, S. J. Dadson, C.-C. Wu, A. H. Sobel, and M.-J. Horng, 2006: Tropical cyclone triggering of sediment discharge in Taiwan. J. Geophys. Res., 111, F03014, doi:10.1029/ 2005JF000428.

Gray, W. M., 1968: Global view of the origin of tropical disturbances and storms. Mon. Wea. Rev., 96, 669-700.

_ 1975: Tropical cyclone genesis. Atmospheric Science Paper 234, Colorado State University, Ft. Collins, CO, 121 pp.

- 1979: Hurricanes: Their formation, structure and likely role in the tropical circulation. Meteorology over Tropical Oceans, D. B. Shaw, Ed., Royal Meteorological Society, 155-218.

Hayakawa, Y. S., and T. Oguchi, 2009: GIS analysis of fluvial knickzone distribution in Japanese mountain watersheds. Geomorphology, 111, 27-37.
Kalnay, E., and Coauthors, 1996: The NCEP/NCAR 40-Year Reanalysis Project. Bull. Amer. Meteor. Soc., 77, 437-470.

Knutson, T. R., J. J. Sirutis, S. T. Garner, G. A. Vecchi, and I. Held, 2008: Simulated reduction in Atlantic hurricane frequency under twenty-first-century warming conditions. Nat. Geosci., 1, 359-364.

- , and Coauthors, 2010: Tropical cyclones and climate change. Nat. Geosci., 3, 157-163.

Korty, R. L., and T. Schneider, 2007: A climatology of the tropospheric thermal stratification using saturation potential vorticity. J. Climate, 20, 5977-5991.

_ , K. A. Emanuel, and J. R. Scott, 2008: Tropical cycloneinduced upper-ocean mixing and climate: Application to equable climates. J. Climate, 21, 638-654.

Landsea, C. W., 2007: Counting Atlantic tropical cyclones back to 1900. Eos, Trans. Amer. Geophys. Union, 88, 197-208.

_ B. A. Harper, K. Hoarau, and J. A. Knaff, 2006: Can we detect trends in extreme tropical cyclones? Science, 313, 452454.

— , and Coauthors, 2008: A reanalysis of the 1911-20 Atlantic hurricane database. J. Climate, 21, 2138-2168.

Lin, G. W., H. Chen, N. Hovius, M. J. Horng, S. Dadson, P. Meunier, and M. Lines, 2008: Effects of earthquake and cyclone sequencing on landsliding and fluvial sediment transfer in a mountain catchment. Earth Surf. Processes Landforms, 33, 1354-1373.

Liu, K.-B., and M. L. Fearn, 1993: Lake-sediment record of late Holocene hurricane actvities from coastal Alabama. Geology, 21, 793-796.

- , and - 2000: Reconstruction of prehistoric landfall frequencies of catastrophic hurricanes in northwestern Florida from lake sediment records. Quat. Res., 54, 238245.

Marsden, A. T., G. A. T. Duller, J. P. Donnelly, H. M. Roberts, and A. G. Wintle, 2009: A chronology of hurricane landfalls at Little Sippewissett Marsh, Massachusetts, USA, using optical dating. Geophormology, 109, 36-45.

McGauley, M. G., and D. S. Nolan, 2011: Measuring environmental favorability for tropical cyclogenesis by statistical analysis of threshold parameters. J. Climate, 24, 5968-5997.

Menkes, C. E., M. Lengaigne, P. Marchesiello, N. C. Jourdain, E. M. Vincent, J. Lefèvre, F. Chauvin, and J.-F. Royer, 2012: Comparison of tropical cyclogenesis indices on seasonal to interannual timescales. Climate Dyn., 38, 301-321, doi:10.1007/ s00382-011-1126-x.

Nolan, D. S., 2011: Evaluating environmental favorability for tropical cyclone development with the method of point downscaling. J. Adv. Model. Earth Syst., 3, M08001, 28 pp.

— clogenesis to wind shear in higher SST environments. Geophys. Res. Lett., 35, L14805, doi:10.1029/2008GL034147.

-, , and K. A. Emanuel, 2007: Tropical cyclogenesis sensitivity to environmental parameters in radiative-convective equilibrium. Quart. J. Roy. Meteor. Soc., 133, 2085-2107.

Nott, J., 2011: Tropical cyclones, global climate change and the role of quaternary studies. J. Quat. Sci., 26, 468-473.

Otto-Bliesner, B., E. C. Brady, C. Gabriel, R. Tomas, S. Levis, and Z. Kothavala, 2006: Last Glacial Maximum and Holocene climate in CCSM3. J. Climate, 19, 2526-2544.

Rappin, E. D., D. S. Nolan, and K. A. Emanuel, 2010: Thermodynamic control of tropical cyclogenesis in environments of radiative-convective equilibrium with shear. Quart. J. Roy. Meteor. Soc., 136, 1954-1971. 
Rasmussen, E. A., and J. Turner, 2003: Polar Lows: Mesoscale Weather Systems in the Polar Regions. Cambridge University Press, $612 \mathrm{pp}$.

Royer, J.-F., F. Chauvin, B. Timbal, P. Araspin, and D. Grimal, 1998: A GCM study of the impact of greenhouse gas increase on the frequency of occurrence of tropical cyclones. Climatic Change, 38, 307-343.

Stark, C. P., and Coauthors, 2010: The climatic signature of incised river meanders. Science, 327, 1497-1501, doi:10.1126/ science.1184406.

Tang, B., 2010: Midlevel ventilation's constraint on tropical cyclone intensity. Ph.D. thesis, Massachusetts Institute of Technology, 195 pp.

_, and K. A. Emanuel, 2010: Midlevel ventilation's constraint on tropical cyclone intensity. J. Atmos. Sci., 67, 1817-1830.

Tippett, M. K., S. J. Camargo, and A. H. Sobel, 2011: A Poisson regression index for tropical cyclone genesis and the role of large-scale vorticity in genesis. J. Climate, 24, 2335-2357.

Vecchi, G. A., and B. J. Soden, 2007a: Effect of remote sea surface temperature change on tropical cyclone potential intensity. Nature, 450, 1066-1070.

, and _ 2007b: Increased tropical Atlantic wind shear in model projections of global warming. Geophys. Res. Lett., 34, L08702, doi:10.1029/2006GL028905.
— , and T. R. Knutson, 2008: On estimates of historical North Atlantic tropical cyclone activity. J. Climate, 21, 3580-3600.

- , and - 2011: Estimating annual numbers of Atlantic hurricanes missing from the HURDAT database (1878-1965) using ship track density. J. Climate, 24, 1736-1746.

Watterson, I. G., J. L. Evans, and B. F. Ryan, 1995: Seasonal and interannual variability of tropical cyclogenesis: Diagnostics from large-scale fields. J. Climate, 8, 3052-3066.

Webster, P. J., G. J. Holland, J. A. Curry, and H.-R. Chang, 2005: Changes in tropical cyclone number, duration and intensity in a warming environment. Science, 309, 1844-1846.

Woodruff, J. D., J. P. Donnelly, K. Emanuel, and P. Lane, 2008: Assessing sedimentary records of paleohurricane activity using modeled hurricane climatology. Geochem. Geophys. Geosyst., 9, Q09V10, doi:10.1029/2008GC002043.

$\longrightarrow,-$, and A. Okusu, 2009: Exploring typhoon variability over the mid-to-late Holocene: Evidence of extreme coastal flooding from Kamikoshiki, Japan. Quat. Sci. Rev., 28, 1774 1785.

Xie, S.-P., C. Deser, G. A. Vecchi, J. Ma, H. Teng, and A. T. Wittenberg, 2010: Global warming pattern formation: Sea surface temperature and rainfall. J. Climate, 23, 966-686.

Xu, K., and K. A. Emanuel, 1989: Is the tropical atmosphere conditionally unstable? Mon. Wea. Rev., 117, 1471-1479. 